\title{
Evaluation and Study of Commercially Available Adhesives
}

\author{
R.S Ghotkar ${ }^{1}$, K.N.Pande ${ }^{2}$, D.R.Peshwe ${ }^{3}$ \\ ${ }^{I}$ Department of Mechanical Engineering, National Institute of Technology, Karnataka, Surathkal-575025, \\ Karnataka, India. \\ ${ }^{2,3}$ Department. Of Metallurgical and Materials Engineering, Visvesvaraya National Institute of Technology \\ (VNIT), South Ambazari road, Nagpur- 440010, Maharashtra, India
}

\begin{abstract}
Since hot melts are "No-Water" compounds, they take very less time to attain peak bonding strength. These compounds penetrate into the bonding surfaces prior to cooling. So if the surface is roughened before applying hot melt, it is better able to adhere itself to the surface. Hot melts should be used with polystyrene or polyethylene substrates. The vinyl acrylate is one of the best adhesives for polyurethane. Also in case of polystyrene, vinyl acrylate leads to the formation of a metallic bond with the young's modulus in the range of GPa (quite abnormal for a non metallic substance like polystyrene). To test the strength of the joints, UTM was used. It revealed the data concerning the bonding strength of various adhesives. X-ray diffraction and FTIR revealed the structures of these adhesives.
\end{abstract}

Keywords: Hot melt adhesive-vinyl acetate-vinyl acrylate-set time-lap joint-butt joint

\subsection{GENERAL INFORMATION}

\section{Introduction}

Plastic welding or heat sealing is the process of welding plastic work pieces together. It is a very common process for joining plastics. Plastic joining is widely used as a means of joining two or more parts of a machine or any instrument or tool by means of various standard methods which are developed and established by studies and researches in this field.

There are several methods of plastic joining. Here it is based on heat sealing. Hot Melts have a relatively brief history in comparison to other adhesives, such as animal glue and hide glue, with their commercial use limited to the past 50-60 years. [7]Hot Melt adhesives are polymer based and are $100 \%$ solids, containing no solvents or water. Hot melt adhesives are thermoplastic, which means they are solid at room temperature but liquefy upon heating and solidify again upon cooling. The lack of water and solvents allow hot melts to attain peak bonding strength very quickly (as soon as they cool). Hot melt adhesives are normally applied at a temperature of about $350^{\circ}$ Fahrenheit. Hot melt adhesives create mechanical bonds, which means that the polymeric components in the hot melt wet out and penetrate the bonding surface prior to solidifying as they cool down again. When adhering to thermoplastic surfaces (plastics, polyolefin laminates, and some coatings), bonding is similar to welding due to the high temperature of the hot melt adhesive during application. Hot melt adhesives are used in a wide variety of industries, such as construction and electronics industries. Metals, plastics and paper are just some of the materials to which hot melt adhesives provide excellent adhesion. Hot melt adhesives are also used in some book binding processes, while others use natural ecoadhesives such as our animal glue.

Hot melts are basically copolymers of ethylene and vinyl acetate and sometimes styrene block copolymers are also used (SBC in case of pressure sensitive hot melt).

Hot melt adhesives are added with tackifying resin to control the adhesion and hot tack properties, wax to control the set time of the resin, antioxidant to improve the pot life and plasticizers or diluents to improve the flow characteristics and modify the viscosity. There are many advantages of HMA as low odour, reduced char, and aggressive bonds, no stringing or tailing, increased mileage (reduced viscosity gain), light in colour, clean machining etc.

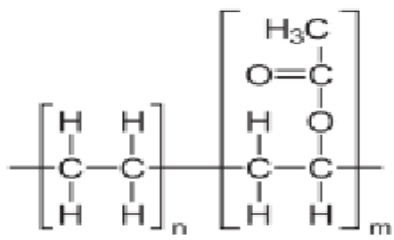

Figure 1 Structure of polyethylene vinyl acetate

[5]The other compound is polyvinyl acetate. This versatile adhesive can be used for finger jointing, edge gluing, hot pressing and radio frequency gluing. Like all adhesives, proper gluing practices are needed to 
achieve stated performance. Advantage of this is that it is highly water-resistant, part cross linking polyvinyl acetate emulsion adhesive with a low minimum use temperature. It is used in famous adhesives like fevicol.<smiles>CCC(C)OC(C)=O</smiles>

\section{Figure 2 Structure of polyvinyl acetate}

[1]The third compound is vinyl acrylate. Vinyl acrylate polymerizes in the presence of a nucleophile. It follows anionic polymerization mechanism. Normally water vapour acts as a source of nucleophile with the help of its $[\mathrm{OH}]^{-}$ions. This leads to formation of long chains and thus leads binding of surfaces. This goes on in the following way.
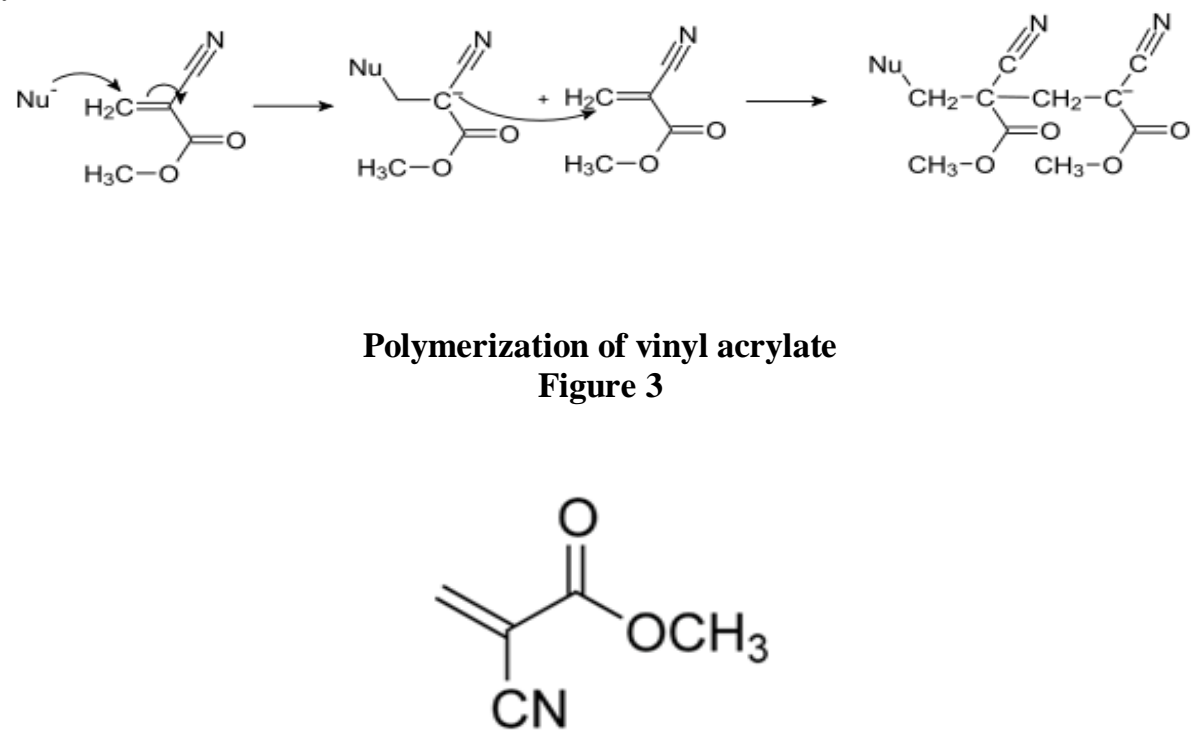

Structure of vinyl acrylate

Figure 4

Famous adhesives like fevikwik have an acrylic base in it.

\subsection{TEST SAMPLE INFORMATION}

\section{Experimental}

The experiment used famous plastics namely polystyrene [high density (HD) and low density (LD)], polyurethane and Teflon.

\subsection{Material sources} were obtained.

All the samples were obtained from APEX POLYMERS. All the samples were used in the form they

\subsection{Processes}

A number of processes were conducted on the samples for the testing of mechanical and structural properties. Initially while testing mechanical properties joint testing was done by using the hot melt adhesive as a sealant. Two types of joints were used for joining the plastics. These joints are made by melting the adhesive on candle or by a hot glue gun and then applying on the joint. Initially the surfaces of these plastics were roughened with an emery paper or by making grooves with a cutter. It was made sure that the grooves made in all cases were of similar size to ensure similar mechanical interlocking. 


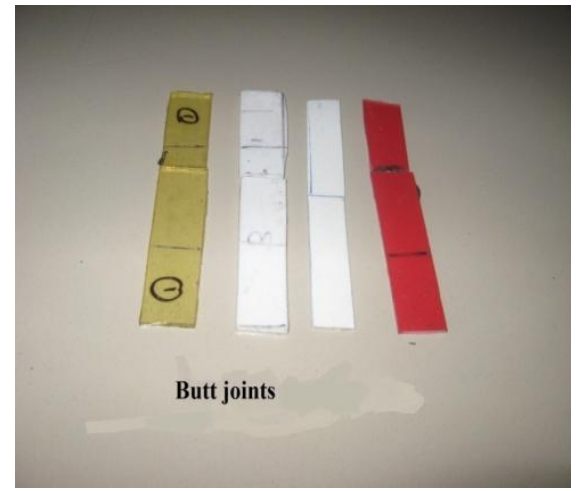

Figure 5 Butt joints for the experiment

(From left) polyurethane, Teflon, polystyrene (LD), polystyrene (HD)

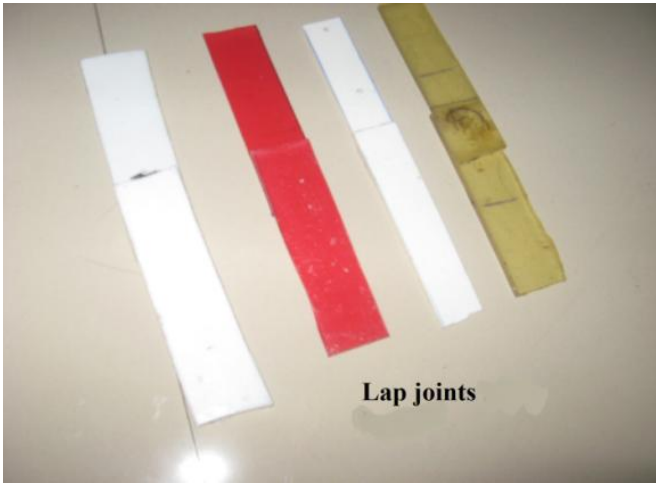

Figure 6 lap joints for the experiment

(From left) Teflon, polystyrene (HD), polystyrene

(LD), polyurethane

\subsubsection{Mechanical testing}

Tensile testing was done by universal testing machine (INSTRON 4467) with different cross head speeds of 10, 20,30 and 50 for different samples. It uses crossheads to pull the substance and induce tensile stress in it. This is used to study the tensile properties of the substance.

\subsubsection{Structural testing}

1) For structural testing of given HOT MELT ADHESIVE, X-Ray diffraction analysis is used. For this a Philips X'Pert Pro PAN-alytical PW 3040/60 X-ray diffractometer was used. The samples were scanned from the angles of $10^{\circ}$ to $100^{\circ}$ using step size of 0.016 and time per step is $10 \mathrm{~s}$. X-ray diffraction is used as a medium for determining the crystal structure of the compound by Bragg's plain's analysis.

2) FTIR analysis was done with a spectrometer using a technique called HATR (horizontal attenuated total reflectance) with angle of incidence if $45^{\circ}$ and number of scans as 8 . FTIR uses IR rays to transmit through the substance and consequently obtain a transmittance vs wave number curve. This curve is imperative in finding the composition of the substance.

\section{Results And Discussion}

The experiments revealed the characteristic properties of different adhesives in the form of various values and graphs. The graphs were from different instruments like XRD and FTIR. These were studied for the chemical properties of the substance. When FTIR analysis was done on the compounds, \%transmittance vs wave number curve was obtained. This curve was useful in predicting the chemical composition of the compound through various standard FTIR tables.

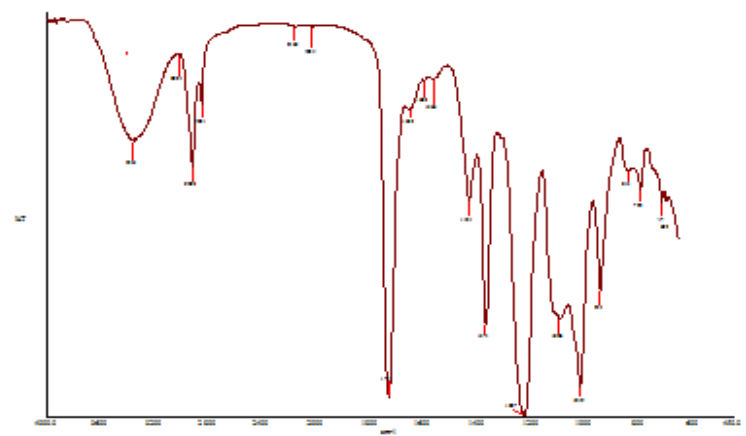

Figure 7 FTIR GRAPH OF POLYVINYL ACETATE 


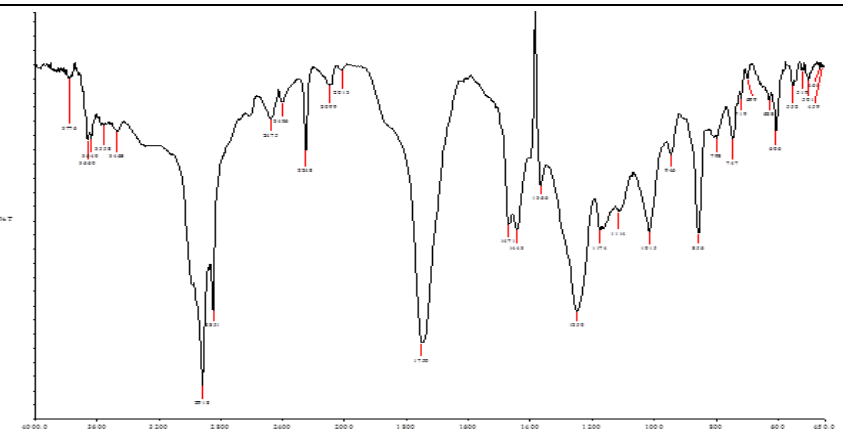

Figure 8 FTIR GRAPH OF VINYL ACRYLATE

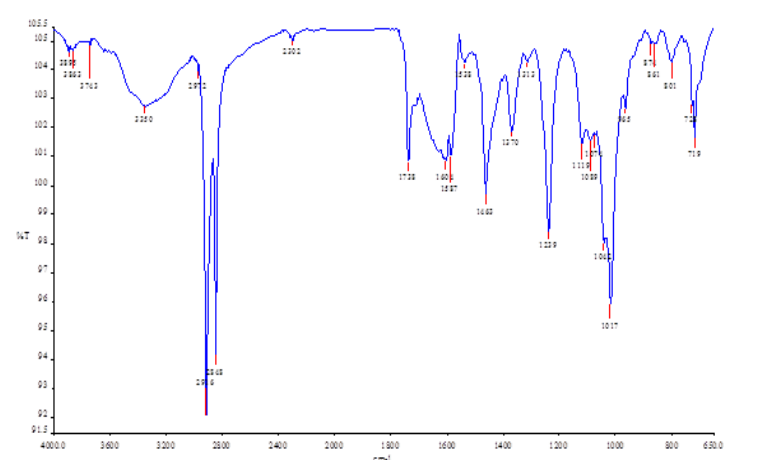

Figure 9 FTIR GRAPH OF HOT MELT ADHESIVE

Basically all the taken adhesives have a peak at around $720 \mathrm{~cm}^{-1}$. This indicates the existence of long chains in the compound. Thus long chains are imperative in formation of bonds by the adhesive. Also there is a stretch at the 1650-1750 range in all three adhesives. This indicates the existence of carbonyl bond in the molecule.

TABLE 1

\begin{tabular}{|l|l|l|l|l|}
\hline SR.NO & POSITION & VIBRATIONS & BOND ORDER & $\%$ T \\
\hline 1. & 3895 & - & - & 104 \\
\hline 2. & 3863 & - & - & 104 \\
\hline 3. & 3743 & - & - & 104 \\
\hline 4. & 3350 & OH( H-BONDED) & Med & 102 \\
\hline 5. & 2972 & $\mathrm{CH}_{2}$ stretch & Strong & 103 \\
\hline 6. & 2916 & $\mathrm{CH}_{2}$ stretch & Strong & 92 \\
\hline 7. & 2848 & $\mathrm{CH}_{2}$ stretch & Strong & 94 \\
\hline 8. & 2302 & - & - & 104 \\
\hline 9. & 1738 & $\mathrm{C}=\mathrm{O}$ bend & Strong & 100 \\
\hline 10. & 1604 & - & - & 100 \\
\hline 11. & 1587 & - & - & 101 \\
\hline 12. & 1538 & - & - & 104 \\
\hline 13. & 1463 & $\mathrm{CH}_{2}$ bend & Med & 99 \\
\hline 14. & 1370 & $\mathrm{CH}_{2}$ bend & Med & 101 \\
\hline 15. & 1313 & $\mathrm{CH}$ wag & Weak & 104 \\
\hline 16. & 1239 & $\mathrm{C}-\mathrm{O}$ stretch & Strong & 98 \\
\hline 17. & 1119 & $\mathrm{C}-\mathrm{O}$ bend & Med & 101 \\
\hline 18. & 1074 & $\mathrm{C}-\mathrm{O}$ bend & Med & 101 \\
\hline 19. & 1042 & $\mathrm{C}-\mathrm{O}$ bend & Med & 98 \\
\hline 20. & 1017 & $\mathrm{C}-\mathrm{O}$ bend & Strong & 95 \\
\hline
\end{tabular}


Evaluation And Study Of Commercially Available Adhesives

\begin{tabular}{|l|l|l|l|l|}
\hline 21. & 965 & CH bend & Weak & 102 \\
\hline 22. & 874 & - & - & 104 \\
\hline 23. & 861 & - & - & 104 \\
\hline 24. & 801 & - & - & 104 \\
\hline 25. & 728 & $\mathrm{CH}_{2}$ rock & Med & 102 \\
\hline 26. & 719 & $\mathrm{CH}_{2}$ long chain & Med & 101 \\
\hline
\end{tabular}

FTIR experiment on the adhesive sample

Also there is a strong stretch in the 1200-1260 range which indicates presence of $\mathrm{C}-\mathrm{O}$ bond in the compound. These are the polar molecules basically responsible for the adhesion in these compounds. Then there are general aliphatic carbon stretches in the all of them at range of around the 2900-2950 mark. There is also this peak at 2248 wave number which indicates the existence of cyanide bond in acrylate.

\subsection{XRD ANALYSIS OF HMA-}

When XRD analysis was done, the curve in figure 10 was the result. Also the XRD analysis of HMA showed that it was a partially crystalline compound, with a peak on an amorphous hump which is the characteristic of a partially crystalline substance.

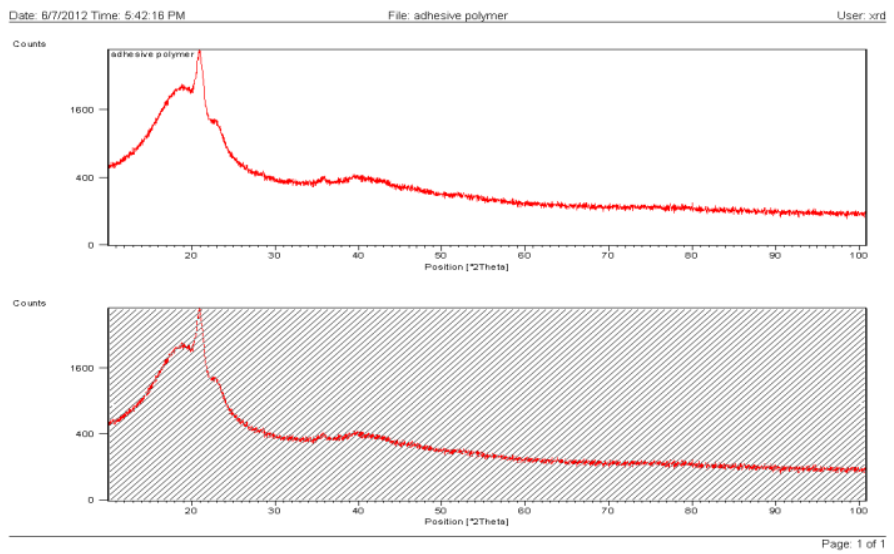

Figure $10 \quad$ XRD diffractograms $(2 \theta$ position $V s$ Intensity counts)

\subsection{TENSILE TEST OF HMA}

When the tensile analysis was done on the samples, they were tested for their tensile strength by pulling the samples by UTM. Table 2 was obtained as a result of this tensile test.

TABLE 2

\begin{tabular}{|l|l|l|l|l|}
\hline SR.NO & Sample (U.T) & $\begin{array}{l}\text { UTS } \\
(\mathrm{Mpa})\end{array}$ & ELONGATION (\%) & YOUNG'S MODULUS (MPa) \\
\hline 1. & $\begin{array}{l}\text { POLYSTYRENE } \\
(\text { HD)(LAP) }\end{array}$ & 14.971 & 0.46 & 717.955 \\
\hline 2. & $\begin{array}{l}\text { POLYSTYRENE } \\
(\text { HD)(BED) }\end{array}$ & 3.581 & 0.76 & 230.048 \\
\hline 3. & $\begin{array}{l}\text { POLYSTYRENE } \\
(\text { HD)(LAP) }\end{array}$ & 14.667 & 0.76 & 659.64 \\
\hline 4. & $\begin{array}{l}\text { POLYSTYRENE } \\
(\text { HD)(BED) }\end{array}$ & 3.994 & 1.23 & 622.809 \\
\hline 5. & $\begin{array}{l}\text { POLYURETHANE } \\
\text { (BED) }\end{array}$ & 0.291 & 1.38 & 0.335 \\
\hline 6. & $\begin{array}{l}\text { POLYURETHANE } \\
(\text { LAP) }\end{array}$ & 1.387 & 0.92 & - \\
\hline 7. & PTFE (LAP) & 1.887 & 1.64 & 398.345 \\
\hline 8. & PTFE (BED) & 1.443 & 8.73 & 150.247 \\
\hline
\end{tabular}




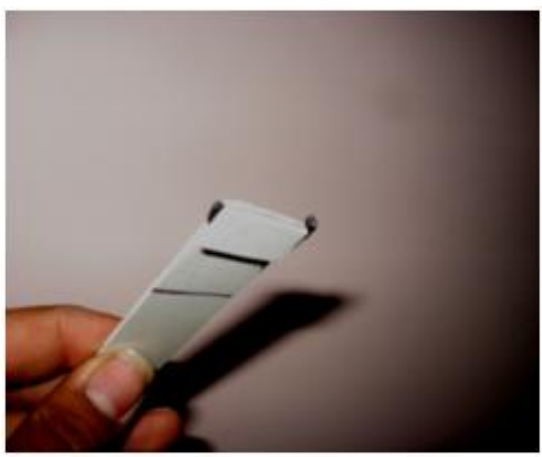

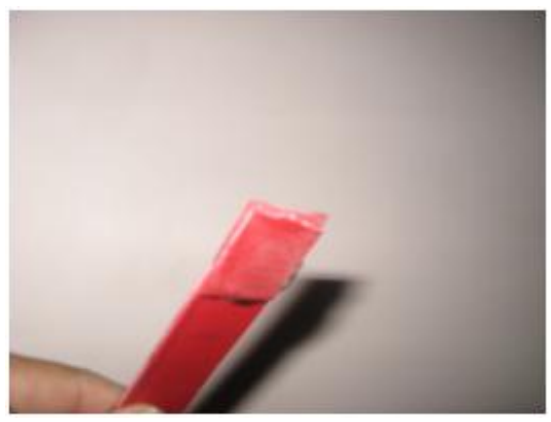

Figure 11b

Figure 11a

[3]As seen in table 2 the percentage elongation in case of HMA is very less. So large strain is not permissible in case of HMA joints. But the strength of the joint is not less. It can handle considerable force. HMA is a very good adhesive when used for polystyrene. Since polystyrene is not stretchable so it does not permit large elongation. Instead the specimen fails before the joint does. This can be seen from the fracture figures (figures 11a and 11b). Here the load taken by the joint is more than the breaking load of the sample of polystyrene. The table 3 shows that around $550 \mathrm{~N}$ force was balanced by the joint. HMA is largely ineffective in case of other material joints. It can be predicted that HMA enters the amorphous polystyrene easily. So it is able to make proper bonds. And it is ineffective in case of Teflon since Teflon is highly crystalline. In case of polyurethane, being a soft material, it cannot provide enough friction to resist. Also as HMA is a non reacting compound, it does not affect polyurethane chemically.

\subsection{TENSILE TEST (COMPARISON)}

The tensile test was performed with taking different adhesives with same substrate materials. Then the data of all the three adhesives was compared for maximum load, uts and young's modulus. A general trend of polyvinyl acetate<vinyl acrylate<HMA was found with a few exceptions which have been highlighted. Other variations in the trend are mostly due to some experimental errors.

(PVA=polyvinyl acetate, VACR=vinyl acrylate, HMA=hot melt adhesive)

TABLE 3

\begin{tabular}{|c|c|c|c|c|c|c|c|c|c|}
\hline \multirow[t]{2}{*}{ SAMPLE } & \multicolumn{3}{|c|}{$\begin{array}{l}\text { LOAD AT PEAK } \\
(\mathrm{kN})\end{array}$} & \multicolumn{3}{|c|}{ UTS(MPa) } & \multicolumn{3}{|c|}{$\begin{array}{l}\text { YOUNG'S } \\
\text { MODULUS } \\
\text { (MPa) }\end{array}$} \\
\hline & PVA & VACR & HMA & PVA & VACR & HMA & PVA & VACR & HMA \\
\hline $\begin{array}{l}\text { POLYSTY } \\
\text { RENE(HD) } \\
\text { (LAP) }\end{array}$ & 0.018 & 0.234 & 0.541 & 0.49 & 6.462 & $\begin{array}{l}14.97 \\
1\end{array}$ & 36.202 & 54.948 & $\begin{array}{l}717.95 \\
5\end{array}$ \\
\hline $\begin{array}{l}\text { POLYSTY } \\
\text { RENE(HD) } \\
\text { (BUTT) }\end{array}$ & 0.027 & 0.105 & 0.129 & 0.757 & 2.986 & 3.581 & $\begin{array}{l}193.39 \\
2\end{array}$ & $\underline{1088.1}$ & $\begin{array}{l}230.04 \\
8\end{array}$ \\
\hline $\begin{array}{l}\text { POLYSTY } \\
\text { RENE(LD) } \\
\text { (LAP) }\end{array}$ & 0.103 & 0.248 & 0.361 & 4.191 & 10.081 & $\begin{array}{l}14.66 \\
1\end{array}$ & $\frac{2321.8}{\underline{6}}$ & $\frac{6270.2}{9}$ & 659.64 \\
\hline $\begin{array}{l}\text { POLYSTY } \\
\text { RENE(LD) } \\
\text { (BUTT) }\end{array}$ & 0.025 & 0.103 & 0.098 & 1.015 & 4.191 & 3.994 & $\begin{array}{l}160.71 \\
7\end{array}$ & 2.132 & $\begin{array}{l}622.80 \\
9\end{array}$ \\
\hline $\begin{array}{l}\text { POLYURE } \\
\text { THANE(L } \\
\text { AP) }\end{array}$ & 0.026 & $\underline{0.280}$ & 0.131 & $\underline{0.274}$ & $\underline{2.971}$ & $\underline{1.387}$ & 9.413 & 89.583 & - \\
\hline $\begin{array}{l}\text { POLYURE } \\
\text { THANE(B } \\
\text { UTT) }\end{array}$ & 0.014 & $\underline{0.292}$ & 0.027 & $\underline{0.154}$ & $\underline{3.099}$ & $\underline{0.291}$ & 13.398 & $\begin{array}{l}\text { 322.99 } \\
9\end{array}$ & 0.335 \\
\hline $\begin{array}{l}\text { TEFLON } \\
\text { (LAP) }\end{array}$ & 0.014 & 0.227 & 0.181 & 0.151 & 2.336 & 1.887 & $\begin{array}{l}112.59 \\
5\end{array}$ & $\begin{array}{l}179.34 \\
1\end{array}$ & $\begin{array}{l}398.34 \\
5\end{array}$ \\
\hline $\begin{array}{l}\text { TEFLON } \\
\text { (BUTT) }\end{array}$ & 0.073 & 0.065 & 0.139 & 0.763 & 0.679 & 1.443 & 82.911 & 0.226 & $\begin{array}{l}150.24 \\
7\end{array}$ \\
\hline
\end{tabular}




\subsection{Standard data for polymers used in experiment}

Table 4 shows the standard data for different quantities required in the experiment determined by well established data obtained from internet (matweb.com for polystyrene), (adhesivetoolkit.com for polyurethane), (bearingworks.com for PTFE)

TABLE 4

\begin{tabular}{|l|l|l|l|}
\hline Sample & Uts $(\mathrm{MPa})$ & Elongation (\%) & $\begin{array}{l}\text { Young's modulus } \\
(\mathrm{MPa})\end{array}$ \\
\hline Polystyrene & $\mathbf{4 0}$ & $\mathbf{7}$ & $\mathbf{1 1 6 0 \pm 3 0 0}$ \\
\hline Polyurethane & $\mathbf{3 8 . 2}$ & $\mathbf{0 . 0 2 6}$ & $\mathbf{3 1}$ \\
\hline PTFE & $\mathbf{1 0 - 4 3}$ & $\mathbf{5 0 - 6 5 0}$ & $\mathbf{4 0 0 - 1 8 0 0}$ \\
\hline
\end{tabular}

[4]Similar strong joint is made when vinyl acrylate is used with polyurethane. The joint formed in this case is very strong. Since polyurethane is extensible, this joint can handle very high strains (upto 200\%). Also, as in case of polystyrene with HMA, the material fails before the joint. And it fails at the same position as the polystyrene sample. Here it can be predicted that since it has strong polar sites in the molecule, it chemically reacts with polyurethane. Also the amorphous nature of polyurethane allows the long chains of poly vinyl acrylate to enter and get properly bonded. This increases the strength of the bond. In case of polystyrene, vinyl acrylate increases the young's modulus of joint compared to the material. That is it increases stresses in the molecule because strain remains more or less the same, since polystyrene is non-stretchable. It increases the young's modulus of polystyrene upto double the original. Similar reason can be employed as of polyurethane as polystyrene is also an amorphous compound. Also in case of Teflon crystallinity of Teflon does not allow the compounds to form strong bonds.

Vinyl acetate bonds are pretty inferior in all the cases. It does not take much load or does any significant change in the joints, except in some cases where it increases the young's modulus of the joint. Vinyl acetate should be used with materials such as wood which provide high friction resistance.

\section{Conclusions}

1. Thus, from the above data, we can say that hot melt adhesive is very good adhesive for polystyrenes and such other amorphous substances. If proper grooving or roughening is done and then the adhesive is applied then it forms very good joints.

2. We can also say that vinyl acrylate or such other strongly polar compounds are very good for polyurethane. It mechanically and chemically adheres to the polyurethane surface and thus leads to a very good bond.

3. Vinyl acetate is a moderately good adhesive for polystyrene and a low grade adhesive for Teflon and polyurethane.

4. All the taken adhesives are largely fruitless with Teflon.

\section{References}

[1] Petrie, E.M., "Adhesion in Extrusion and Co-extrusion Processes", Omnexus4AdhesivesandSealants, July 2008.

[2] Socrates, George, Infrared and Ramen Characteristic Group Frequencies, Wiley, Chichester, 2001.

[3] Hot melt applications - Ethylene Copolymers Center. SpecialChem4Adhesives. Retrieved on 2010-02-08.

[4] F. London, "The General Theory of Molecular Forces" (1936).

[5] Fritz Klatte and Adolf Rollett, "Plastic composition and process of producing it," U.S. Patent 1,241,738 (filed: July 3, 1914; issued: Oct. 2, 1917), an abstract of which appears in the Journal of the Society of Chemical Industry (London), vol. 36, page 1185 (1917).

[6] Handbook of adhesives and sealants By Edward M. Petrie, McGraw-Hill, 2007 ISBN 0-07-147916-3.

[7] Ethylene Vinyl Acetate (EVA) Copolymers ( $>50 \%$ Ethylene) Market Study Report - European Adhesives Industry. Chemquest.com. Retrieved on 2010-02-08.

\section{Acknowledgements}

I am thankful to the VNIT department of Metallurgy and Materials for providing all the facilities of using the machines .I would especially like to thank all other Ph.D scholars and other staff of department of Metallurgy and Materials for the full support and help provided during my project period. 